\title{
THE LOCAL BLOOD FLOW IN HUMAN BONE MARROW IN LEUKEMIA AND NEOPLASTIC DISEASES AS DETER- MINED BY THE CLEARANCE RATE OF RADIOIODIDE $\left(\mathrm{I}^{131}\right)^{1}$
}

\author{
By N. L. PETRAKIS, S. P. MASOUREDIS, 2 ANd PATRICIA MILlER, with the \\ TECHNICAL ASSISTANCE OF FAUNO L. CORDES \\ (From the Laboratory of Experimental Oncology, National Cancer Institute, National Insti- \\ tutes of Health, Public Health Service, Department of Health, Education, and Welfare, \\ and the Division of Medicine and Cancer Research Institute, University of \\ California School of Medicine, San Francisco, Calif.)
}

(Submitted for publication December 1, 1952 ; accepted June 6, 1953)

Although considerable information has been obtained on the rate of blood flow in many organs (1), few data have been reported on the blood flow in human or animal bone marrow (2). The neglect of this aspect of marrow physiology is probably due to the technical difficulties encountered in gaining access to the blood vessels of this diffuse organ in the intact animal or man.

The extensive application of the radioisotope clearance technique described by Kety $(3,4)$ for the estimation of the regional circulation in muscle, liver, subcutaneous tissues, brain tissue, and skin (4-10) suggested its use as a clinically applicable method for the evaluation of the effective local blood flow in the human bone marrow. This method is based on the premise that if a diffusible tracer substance is introduced into a tissue its clearance or removal is a function of all possible factors contributing to the local blood flow at the site of injection.

In the present study, the relative rates of clearance of $\mathrm{I}^{181}$ from the bone marrow were determined in patients with various malignant diseases and leukemia. The radioiodide was injected into the bone marrow through a standard bone marrow needle, and the rate of disappearance of the isotope was measured with a GeigerMueller counter. In addition, simultaneous determinations of $\mathrm{I}^{181}$ clearance rates from the gastrocnemius muscle were obtained for comparing the clearance rates obtained in the bone marrow

\footnotetext{
1 Presented in part at the Annual Meeting of Western Section of the American Federation for Clinical Research, Carmel, California, January 24, 1952.

2 Postgraduate Research Fellow, National Cancer Institute.
}

with those found in an anatomically and physiologically different vascular bed.

\section{MATERIALS AND METHODS}

Clinical material: Forty-three patients with a variety of malignant diseases and leukemia were studied (Table I). The patients were grouped into seven major groups as indicated in Table I. They varied in weight from 28 to 91.6 kilo, and all had normal blood pressures except M. D. and E. H., whose pressures were $175 / 110$ and $160 / 110$, respectively (Table $I$ ). The subjects were studied under resting but not basal conditions. The environmental temperature varied from 20 to $25^{\circ} \mathrm{C}$.

Marrow techrique: The sternal marrow and the gastrocnemius muscle were studied simultaneously in each patient (Table I). In a few subjects the tibia and the ilium were employed. The iliac crest site was approximately two centimeters posterior to the anterior superior spine of the ilium and the tibia was studied at the tibial tubercle.

The marrow site was aseptically prepared and locally anesthetized with 2 per cent procaine infiltration of the skin, subcutaneous tissue and periosteum. A short Turkel needle was advanced into the bone with a rotary motion until the marrow cavity was entered. The radioiodide was then introduced into the marrow tissue by means of a tuberculin syringe with a No. 22 gage 4-inch needle inserted through and embedded well beyond the tip of the bone marrow needle. The $\mathrm{I}^{12}$, as sodium iodide, was slowly injected, usually requiring one to two minutes. A slow rate of injection was used to minimize pain and to avoid a sudden increase of intramedullary pressure which conceivably might affect the rate of clearance of the $\mathrm{I}^{\mathrm{m}}$. By placing the point of the No. 22 gage needle well into the marrow and slowly injecting the radioactive material, it was possible to prevent skin contamination by reflux of marrow blood and $I^{201}$ into the marrow needle. Following the injection of $I^{121}$ both needles were withdrawn from the marrow and pressure was immeditely applied to prevent bleeding into the subcutaneous tissues and onto the skin. The puncture site was cleaned with alcohol to remove possible radio- 


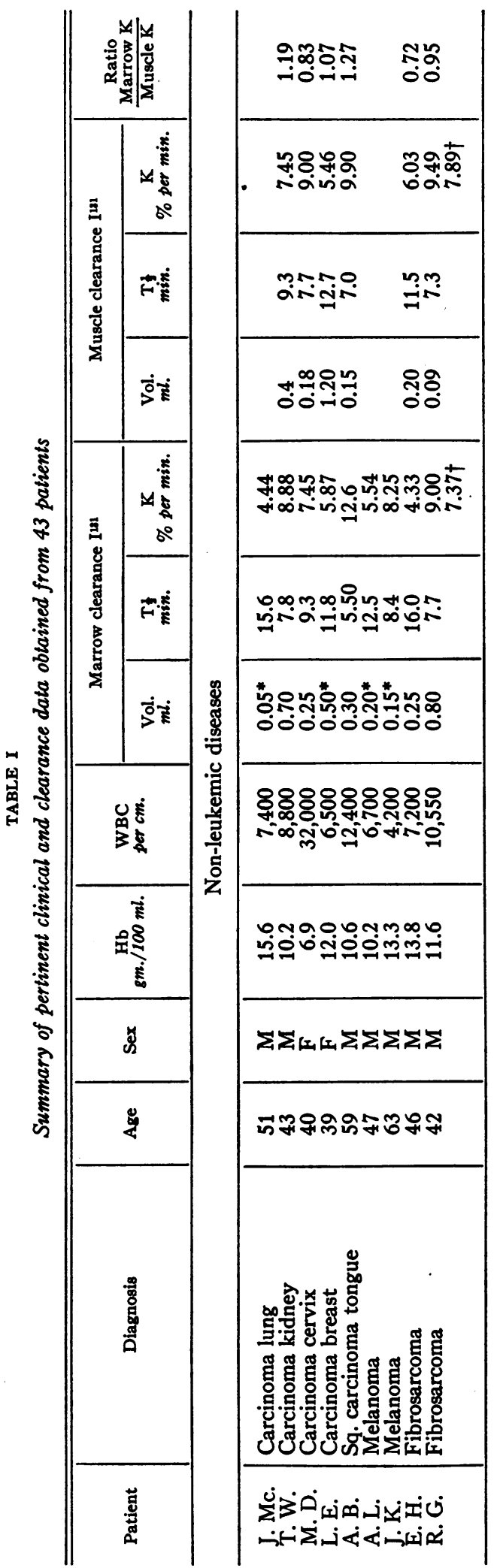

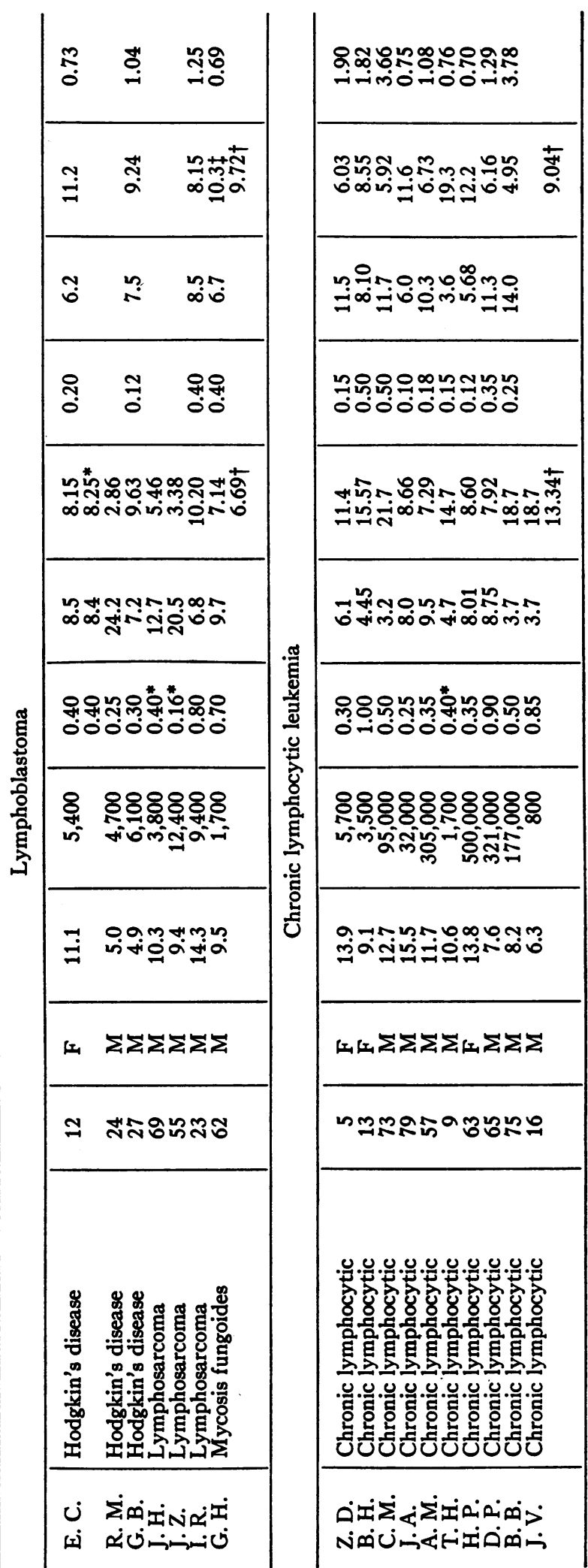


N. L. PETRAKIS, S. P. MASOUREDIS, AND PATRICIA MILleR

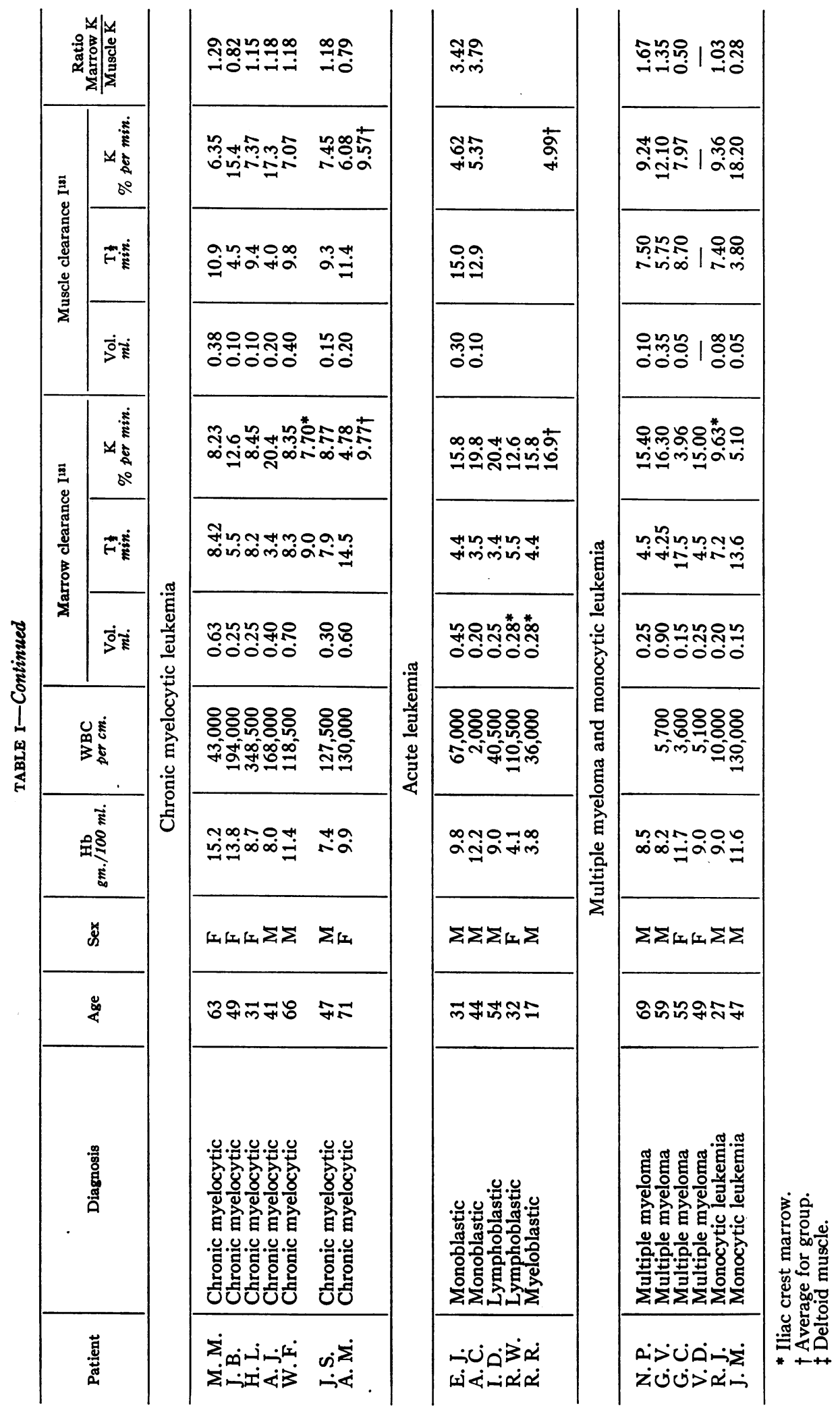


active contamination, and the wound was sealed with collodion.

Marrow was obtained for cytological examination at the end of counting procedure in most instances. In a few patients, however, 0.1 to $0.2 \mathrm{cc}$. of marrow was obtained at the start of the study without demonstrable alteration in clearance. In the later instances care was taken to inject the $I^{181}$ well beyond the point of the aspiration. Routine differential counts of the marrow samples were made with both supravital and Wright stained fixed preparations. Usually 200 cells were counted for the differentials.

In most patients, $\mathrm{I}^{131}$ clearance rates of the gastrocnemius muscle were simultaneously determined, except where noted (Table I). The radioiodide was injected into the belly of the muscle by means of a tuberculin syringe with a No. 26 gage $11 / 2$ inch hypodermic needle.

Physiologic and pharmacologic studies designed to demonstrate the effect on $\mathrm{I}^{13 \mathrm{~s}}$ clearance of altered systemic circulatory dynamics were carried out in a few subjects. These included exercise, phlebotomy and the intravenous injection of Paredrine ${ }^{3}$ and of Bistrium bromide (Squibb). 4

Determination of radioactivity: From 100 to 400 micrograms of iodide and from 10 to 30 microcuries of $\mathrm{I}^{121}$ were used in all determinations. The radioiodide was made up in isotonic phosphate buffer, $\mathrm{pH} 7.5$, solution containing carrier potassium iodide. The volume of radioiodide injected per patient is shown in Table $I$. Surface counting was carried out with a lead-shielded $(1.25 \mathrm{~cm}$. thick) Victoreen or Tracerlab mica endwindow counting tube mounted on an adjustable stand. The window thickness of the tubes varied from 3.5 to $1.8 \mathrm{mg}$. per $\mathrm{cm}^{2}$. The window-to-tissue distance was $0.5 \mathrm{~cm}$. In addition, two layers of gauze were interposed between the counting tube and the skin over the marrow site. The radiation detected in the marrow under these conditions of geometry is predominantly gamma radiation. The Geiger-Mueller tubes were coupled to two conventional scalers, one tube being used for the marrow study and the other for the muscle determination. Each injection site was counted for a total of 1,024 counts, every 30 to 60 seconds. The counting was carried out for fifteen to thirty minutes after injection. In all cases the counts were greater than ten times background.

Failure to obtain a decrease in counting rate with respect to time was indicative of gross skin contamination by radioiodide. The high efficiency of our tube for beta radiation and the absence of a physiological mechanism for removal of $I^{121}$ from the skin provided an extremely sensitive measure of skin contamination. Where skin contamination occurred, an attempt was made to resume counting after careful cleansing with 70 per cent alcohol. Data were rejected if counting could not be started within three minutes after the injection of $I^{\text {mat }}$. Data were also rejected if a single exponential decrease did not occur within the first 15 to 30 minutes

\footnotetext{
8 B-4-hydroxyphenylisopropylamine.
}

4 Hexamethonium bromide. after injection. Skin contamination not sufficient to obscure marrow clearance was manifested by failure to obtain a single exponential decrease, since the $I^{212}$ on the skin would contribute an essentially constant number of counts to the counting rate during the time of the study. Skin contamination did not occur with the muscle studies since the $I^{181}$ was injected into the muscle from a lateral position. This enabled counting to be done over skin that was out of the puncture site.

Studies were made to ascertain whether the radioactivity being measured was actually in the bone marrow and that the clearance curves were not significantly influenced by extravasation of minute amounts of blood containing radioiodide into the subcutaneous tissues. Marrow clearances were made employing aluminumshielded (1.96 mg. per $\mathrm{cm}^{2}$ ) Geiger tubes. Counting was continued until the clearance curve was established, after which the aluminum shield was removed and the curve again determined. The clearance curves obtained in this manner were not significantly different, indicating that the radioiodide was injected into the bone marrow and that practically no contamination of the subcutaneous tissue occurs under.the conditions of the technique employed here. The error that results from such extravasation would decrease the clearance rate but would not detract from the positive findings reported here.

Calculations: The activity in counts per second was plotted against time on semilogarithmic paper. In all cases studied, the results could be described as a single, decreasing exponential function. While other studies (8) have indicated that the disappearance curve is a complex function, our studies were based on the initial component which was logarithmic and extended through the first 15 to 30 minutes. In a few cases other components developed later. The present studies were completed within 20 minutes in most cases. The results are expressed both as half-time in minutes ( $\mathrm{T} 1 / 2)$, and as clearance constant $(K)$, which is the per cent administered radioiodide removed per minute, as obtained from the expression $K=\frac{0.693}{T 1 / 2}$.

To determine the statistical significance of the clearance constant derived from the plot of the data on semilogarithmic paper, the regression line was determined and the standard deviation of the half-time of the regression line was calculated (Mather, K., Statistical analysis in biology, Chapter VIII. Interscience Publ. Inc., New York, 1947) in four representative patients for marrow and muscle. It can be seen that the experimental data fit an exponential function and that there is a significant difference between marrow clearances of different patients as well as significant differences between the marrow and muscle clearances in some of the patients (Figure 1).

Radiation dosage calculations: For calculation of the radiation received by the bone marrow, certain simplifying assumptions were made: 


\section{IODIDE (1 $\left.{ }^{13}\right)$ CLEARANCE FROM STERNAL MARROW AND GASTROCNEMIUS MUSCLE}
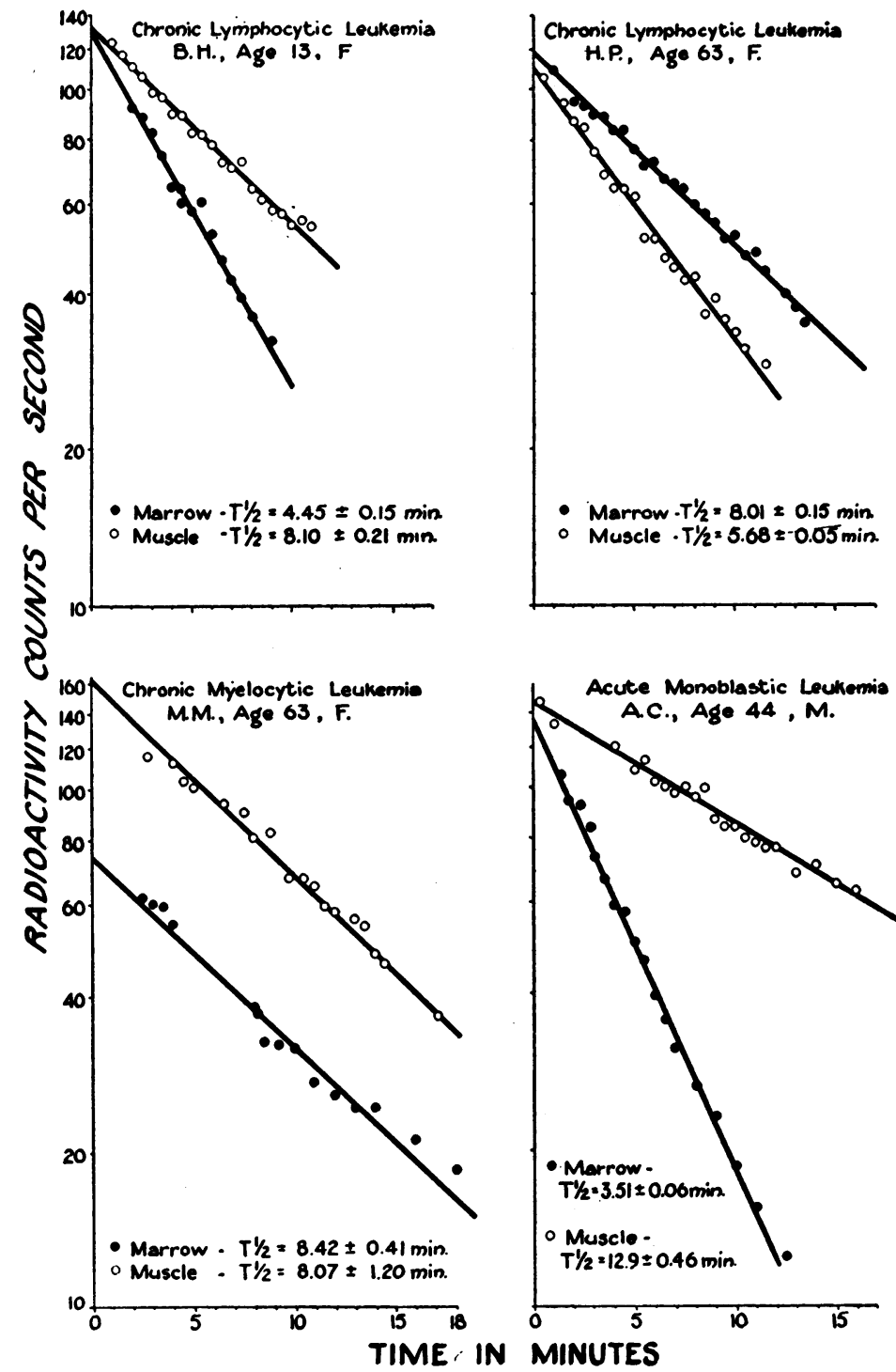

Fig. 1. Counts Per Minute of I ${ }^{19}$ Plotted Semilogarith mically against Time for Sternal Marrows and Gastrocnemius Muscles in Four Patients with Leukemia

The half time of the regression line and the standard deviation of the half time are demonstrated.

(a) The depth of the sternal marrow cavity was assumed to be approximately one centimeter.

(b) Since less than $1 \mathrm{ml}$. of a solution containing less than 25 microcuries of $\mathrm{I}^{131}$ was administered, it was assumed that the greatest amount of radiation was confined to $1 \mathrm{~cm}^{3}$ of bone marrow tissue.

(c) In this volume the gamma ray energy contribution was considered to be negligible. (d) No selective metabolic localization of $\mathrm{I}^{182}$ occurred in the bone marrow.

(e) The large dilution of $I^{181}$ in the systemic iodide space, and the relatively rapid excretion of $I^{181}$ (11), contributed only a small amount of the radioactivity to the marrow by recirculation and was considered insignificant.

(f) The effect of physical decay of $\mathrm{I}^{181}$ was considered 
insignificant (half-life eight days) because of the much more rapid rate of removal of the $I^{181}$ from the marrow site.

With these assumptions the irradiation to 1 gram of bone marrow from beta-particles with 30 microcuries of $\mathrm{I}^{121}$ is 0.260 rep. per min. (10). The total accumulated dose (complete removal of isotope from the site of injection) is 3.70 rep. Only about 0.07 per cent of the bone marrow receives this radiation, assuming a marrow volume of $1,400 \mathrm{cc}$. Clinically no evidence of hematopoietic dysfunction attributable to the radiation used in these studies could be detected.

The thyroid uptake of $\mathrm{I}^{181}$ resulting from marrow and muscle studies was determined in four patients at 6 and 24 hours, and was found to range from 15 to 25 per cent of the total administered dose. This represents 6 to 10 microcuries.

\section{RESULTS}

Forty-three patients with various neoplastic diseases, lymphoblastomas, and leukemia were studied. The half time $\left(T^{1} 1 / 2\right)$ and $K$ values (per cent administered radioactivity removed per minute) for the bone marrow and muscle in each patient are presented in Tables I and II. Representing curves from four patients are shown in Figure 1. The distribution of the individual $\mathrm{K}$ values in the leukemic and non-leukemic patients is shown in Figure 2. In a patient with Hodgkin's disease (E. C.), simultaneous clearance studies on the sternum and iliac crest yielded almost identical results. The $K$ values were closely grouped in the non-leukemic patients and in the patients with lymphoblastoma, with an average of 7.3 per cent $\mathrm{I}^{131}$ cleared per minute, ranging from 2.86 to 12.6 per cent. In the acute leukemias the average $\mathrm{K}$ value was 16.9 per cent per minute, ranging from 12.6 to 20.4 per cent, indicating that the injected iodide was removed from the marrow at a more rapid rate than in non-leukemic patients. In chronic lymphocytic leukemic patients there was a spread of $\mathrm{K}$ values from 7.29 per cent to 21.7 per cent per minute. Most of the $\mathrm{K}$ values for the myelocytic leukemia patients were in the range of the values obtained in the non-leukemic patients, 4.78 to 8.66 per cent per minute, except for patients J. B. and A. J. who had more rapid clearance rates. The two patients R. J. and J. M. with monocytic leukemia had clearance values of 9.63 per cent and 5.10 per cent, respectively. In four patients with multiple myeloma, three (N. P., G. V., and V. D.) had elevated $K$ values, $15.4,16.3$, and 15.0 per cent, respectively, while the fourth patient (G. C.) had a low rate of 3.96 per cent.

There was no apparent correlation between the marrow clearance rates and the hemoglobin level, leucocyte count, weight, body temperature, and blood pressure (Figure 2). Although the volume of $\mathrm{I}^{131}$ in these experiments varied from 0.05 to $1.0 \mathrm{ml}$., there was no clearly demonstrable relationship between volume of injected $\mathrm{I}^{131}$ and clearance rate. Rapid clearance rates were obtained with both large and small volumes of $\mathrm{I}^{131}$. The average volumes injected are indicated in Table I, and it can be seen that they did not vary more than $0.3 \mathrm{ml}$. for the marrow studies, and $0.2 \mathrm{ml}$. for the muscle studies.

In all the patients studied, the muscle $K$ values were similar, approximately 8 to 10 per cent of the $\mathrm{I}^{131}$ removed per minute (Tables $\mathrm{I}$ and II). In the acute leukemia group, muscle clearances were obtained on only two patients, 4.62 and 5.37 per cent, respectively. One patient with monocytic leukemia had a muscle clearance of 18.2 per cent $\mathrm{I}^{131}$ removed per minute.

TABLE II

Averages of marrow and muscle clearance constants and ranges in 43 patients

\begin{tabular}{|c|c|c|c|c|c|c|}
\hline & \multicolumn{3}{|c|}{ Bone marrow } & \multicolumn{3}{|c|}{ Muscle } \\
\hline & $\begin{array}{l}\text { No. } \\
\text { cases }\end{array}$ & $\begin{array}{c}\text { Average } \\
\mathbf{K}\end{array}$ & Range & $\begin{array}{c}\text { No. } \\
\text { cases }\end{array}$ & $\begin{array}{c}\text { Average } \\
\mathbf{K}\end{array}$ & Range \\
\hline Non-leukemic & 9 & 7.37 & $4.33-12.6$ & 6 & 7.89 & $5.46-9.90$ \\
\hline Lymphoblastoma & 7 & $\begin{array}{c}\frac{6.69}{14.06} \\
\text { Av. } 7.03\end{array}$ & $2.86-10.2$ & 4 & $\begin{array}{r}\frac{9.72}{17.61} \\
\text { Av. } 8.31\end{array}$ & $8.15-10.3$ \\
\hline $\begin{array}{l}\text { Lymphatic leukemia } \\
\text { Myelocytic leukemia } \\
\text { Monocytic leukemia } \\
\text { Multiple myeloma } \\
\text { Acute leukemia }\end{array}$ & $\begin{array}{r}10 \\
7 \\
2 \\
4 \\
5\end{array}$ & $\begin{array}{l}13.41 \\
10.3 \\
7.36 \\
13.4 \\
16.9\end{array}$ & $\begin{array}{c}7.29-21.7 \\
4.78-20.4 \\
5.10-9.63 \\
3.96-16.3 \\
12.6-20.4\end{array}$ & $\begin{array}{l}9 \\
9 \\
2 \\
3 \\
2\end{array}$ & $\begin{array}{c}9.16 \\
9.65 \\
13.7 \\
9.77 \\
4.16\end{array}$ & $\begin{array}{l}6.03-19.3 \\
6.08-17.3 \\
9.36-18.2 \\
7.97-12.1 \\
4.62-4.70\end{array}$ \\
\hline
\end{tabular}



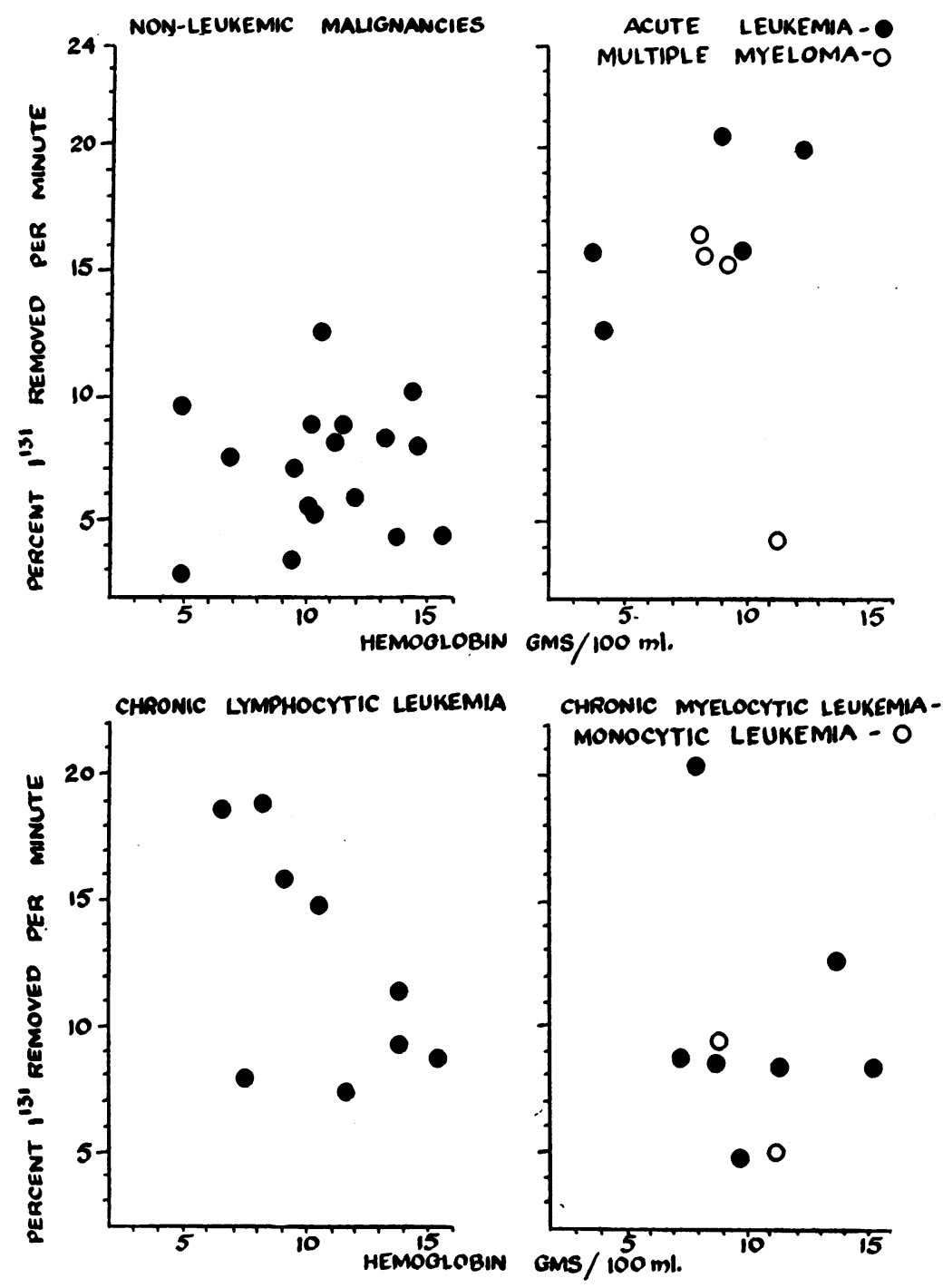

Fig. 2. Per Cent of Im Cleared from the Marrow Per Minute Plotted against the Hemoglobin Concentration

The relationship between marrow clearance and muscle clearance is presented as a ratio of marrow $\mathrm{K}$ to muscle $\mathrm{K}$ (Table $\mathrm{I}$ ). These ratios are plotted against hemoglobin in Figure 3. The ratios of the non-leukemic, lymphoblastoma, and chronic myelocytic groups fall between 0.6 and 1.4 (Figure 3 ). In the group of chronic lymphocytic leukemia patients there was a scatter of the ratio values from 0.80 to 4.0 , with five patients below and four above 1.4. In the two patients with acute leukemia the ratios were 4.1 and 3.42 . The two patients with monocytic leukemia had ratios of 1.03 and 0.28 , and in three cases of multiple myeloma, ratios of $1.67,1.35$, and 0.50 were obtained, respectively.

Although a wide distribution of $\mathrm{Hb}$ was present in all groups of patients, there appears to be no direct relationship between the marrow to muscle ratio and the hemoglobin concentration (Figure 3).

In a few patients it was possible to make additional clearance studies in order to ascertain the degree of reproducibility of the technique in the marrow. The data obtained in four patients are shown in Table III. 


\section{DISCUSSION}

The validity of the radioisotope clearance method as a measure of effective local circulatory efficacy at the injected site was demonstrated theoretically and experimentally by Kety $(3,4)$. Stone and Miller (13) experimentally demonstrated that the radioactive sodium $\left(\mathrm{Na}^{24}\right)$ disappearing from the site of injection in the dog muscle can be quantitatively recovered in the venous blood draining the area of injection. Little or no radioactivity was recovered in the lymphatics draining the area. Subsequent studies by others $(4-10)$ have supported the contention that locally injected radioisotopes can be used to determine the effective local blood flow in muscle and skin utilizing $\mathrm{Na}^{24}$ and $\mathrm{I}^{181}$. Minor unexplained discrepancies have been detected between the clearance rates obtained with these two isotopes (8).

The extension of the Kety technique to a rigidly enclosed and trabeculated organ such as the bone marrow raises a question as to its validity as an index of regional blood flow in this organ. Certain experimental conditions which would be expected to affect the systemic blood flow were employed to demonstrate the validity
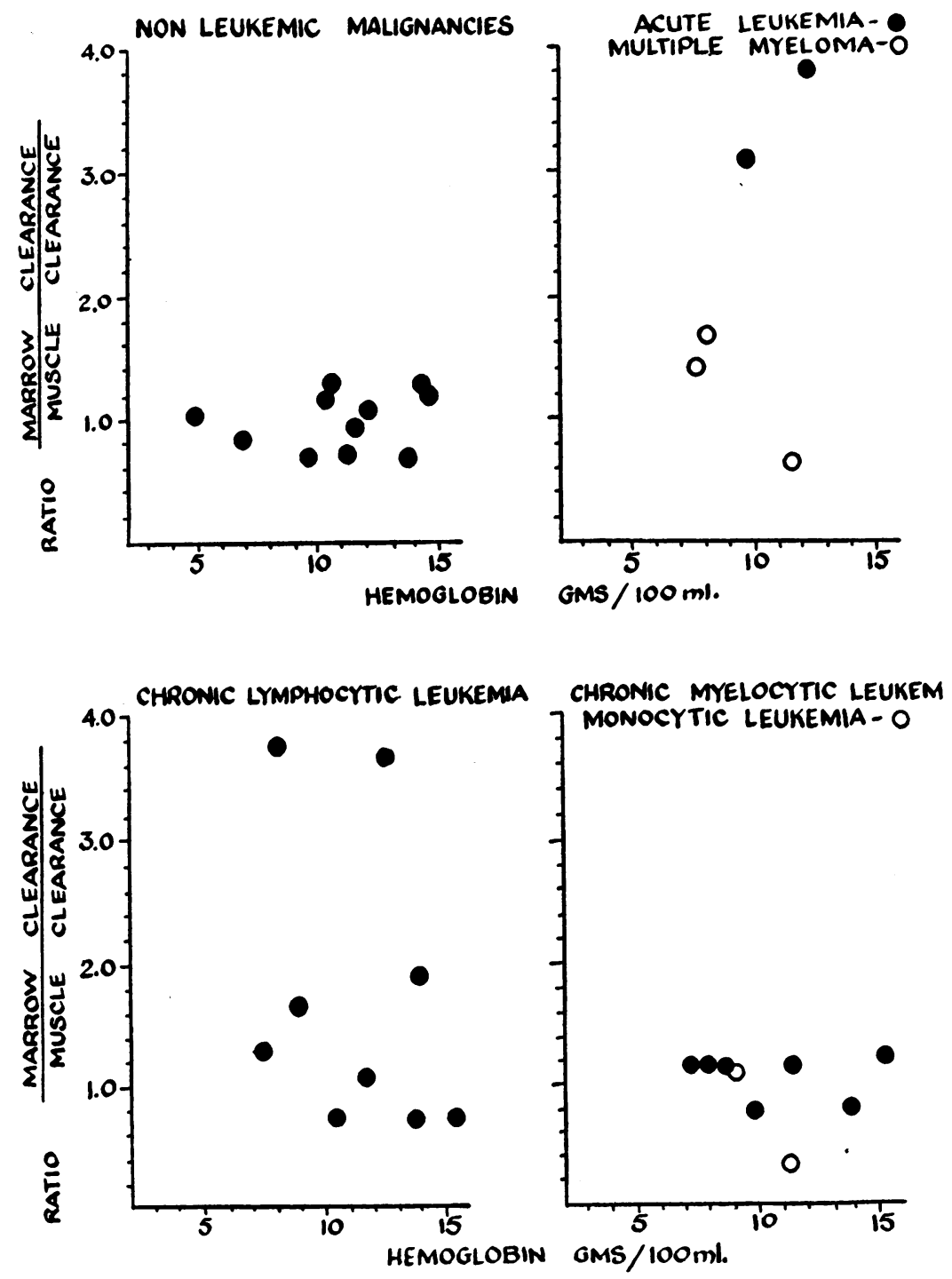

Fig. 3. Ratio of Marrow Clearance $\mathrm{K}$ to Muscle Clearance $\mathrm{K}$ Plotted against Hemoglobin Concentration 
TABLE III

Demonstrating reproducibility of bone marrow clearance constants

\begin{tabular}{cclr}
\hline \hline Patient & Date & \multicolumn{1}{c}{ Site } & Marrow K \\
\hline W. F. & $9 / 6 / 51$ & Sternum & 11.2 \\
& $9 / 6 / 51$ & Sternum & 12.2 \\
R. G. & $9 / 13 / 51$ & Sternum & 11.1 \\
& $9 / 14 / 51$ & Sternum & 13.2 \\
E. C. & $7 / 23 / 51$ & Sternum & 8.2 \\
& $7 / 23 / 51$ & Tibia & 8.3 \\
T. H. & $7 / 23 / 51$ & Tibia & 18.2 \\
& $9 / 6 / 51$ & Ilium & 15.0 \\
\hline
\end{tabular}

of this technique in bone marrow. Following the intravenous injection of hexamethonium bromide, a ganglionic blocking agent, both the marrow and the muscle clearance rates became very slow and appeared to be directly related to the pronounced fall in blood pressure which resulted (Figure 4). Conversely, the injection of Paredrine resulted in a distinct increase in the clearance rate from the marrow, presumably as a result of the sympathomimetic action of this drug. These preliminary experiments indicated that alterations in the systemic circulation are reflected in the $\mathrm{I}^{131}$ clearance rate from the bone marrow. It is therefore felt that the alterations in the bone marrow clearance rate produced by these pharmacologic agents further support the interpretation that the clearance technique is a measure of effective blood flow.

Of the many factors which could conceivably influence the clearance rate of $\mathrm{I}^{181}$ in the marrow, the volume of fluid injected is an important consideration. The sudden injection of a volume of fluid could possibly produce a local increase in tissue pressure which in turn might increase the initial rate of removal. With respect to bone marrow, the $I^{131}$ was injected slowly, without pain, and a period of 1 to 2 minutes elapsed before counting was begun. This interval of time allowed decompression of the injected site to occur. In many of the cases, especially in those patients with acute leukemia and chronic lymphocytic leukemia, the injected $\mathrm{I}^{181}$ was literally aspirated into the marrow, indicating that no pressure developed from the injection. The role of the lymphatic drainage of $\mathrm{I}^{181}$ in the marrow is difficult to evaluate. However it is probably negli- gible, since no anatomic evidence for a lymphatic system in this organ has been presented (14).

Table III shows the degree of reproducibility of the marrow clearance values in the same patient on different occasions. Despite the technical difficulties encountered in making marrow clearance studies, it can be seen that a good agreement is obtained on repeated determinations.

The vascularity of the bone marrow is well recognized. It was demonstrated by Tocantins, O'Neill, and others that many substances, including blood, plasma, medications, and diagnostic agents, when injected into the marrow cavity rapidly appear in the systemic circulation $(15,16)$. Tocantins reported that fluids could be administered at a rate of from $0.4 \mathrm{cc}$. to $25 \mathrm{cc}$. per minute into the marrow, but this rate probably does not reflect the peak capacity for the removal of solutions injected into the marrow cavity because of changes in intramedullary pressure and physical disruption of the marrow vascular bed. These factors as well as the resistance to flow provided by the tubing, needle, and clotting of marrow blood probably exert a marked and variable effect on the rate of flow of substances introduced into the marrow. Jones (2) has estimated the rate of human hematopoietic marrow flow to be approximately $300 \mathrm{cc}$. per min. based on data obtained on rabbits in radioactive colloid uptake studies by the marrow.

The data obtained in the present study indicate that the clearance rates of $\mathrm{I}^{181}$ in such divergent types of vascular beds as bone marrow and resting muscle are essentially identical in patients with various malignancies, Hodgkin's disease and lymphosarcoma. These rates are considerably less than those reported by Wechsler, Sokoloff, and Kety (6) for human liver, where 34 to 48 per cent of the injected isotope was removed per minute. Striking increases were observed in the $\mathrm{I}^{181}$ clearance rates in the bone marrow in leukemic patients. The rapid clearance of radioiodide from the marrow in all the cases of acute leukemia, in half of those with chronic lymphatic leukemia, and in two of the three patients with multiple myeloma suggests that the marrow vascularity in these conditions is abnormal. In the patients with chronic myelocytic and monocytic leukemia studied, the clearance rates were similar to those found in the non-leukemic group of patients.

In an attempt to dissociate the systemic circula- 


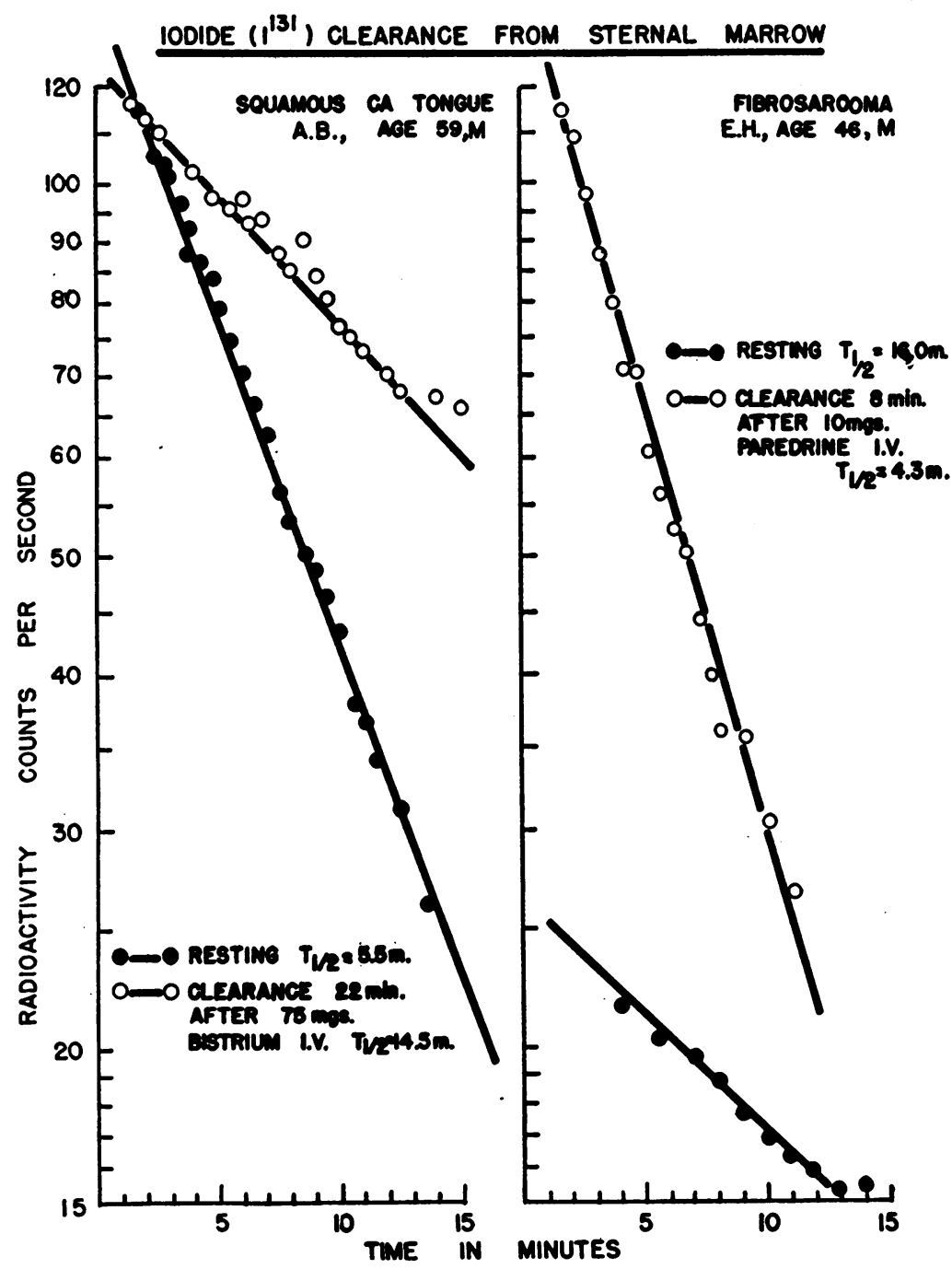

Fig. 4. Alterations Produced in I ${ }^{\text {min }}$ Clearance from the Marrow FolLOWINg the INJection OF Bistrium aNd Paredrine

tory influence on the local bone marrow flow, the data were expressed as a ratio of marrow $\mathrm{K}$ to muscle $\mathrm{K}$. This ratio should serve to minimize the effect of any generalized increase in the cardiac output on the marrow clearance rate, such as might occur in exercise, emotional stress, anemia, etc. It will be noted that in all the patients studied, with the exception of those patients with acute leukemia, chronic lymphatic leukemia, and myeloma, the ratio of marrow $K$ to muscle $K$ falls below 1.4. It is felt that a clearly demonstrable specific local increase in marrow blood flow is present in those diseases with ratios above 1.4.

The demonstration of increased $\mathrm{I}^{131}$ clearance rates in the bone marrow in leukemia might be anticipated since these diseases have been considered to be neoplasms of the hematopoietic system (17). Many types of rapidly proliferating tumors have been demonstrated to elicit the formation of a vascular stroma $(18,19)$. The marked divergence between clearance rate found in those patients with acute and lymphocytic leukemia, and those with myelocytic and monocytic leukemia is of interest. The present findings indicate that fundamental differences may exist in the anatomy and physiology of the marrow vascular systems among the various human leukemias.

There is a lack of anatomical data on the vas- 
cularity of both normal and pathological human bone marrow. A number of investigators $(15,20$, 21) have attempted to visualize the sternal marrow vascular bed by injection of radiopaque substances, but these studies were unsatisfactory for the finer details of vascularity. No studies similar to those of Doan (22) in the pigeon were found for man. In observations made on histological sections of post-mortem bone marrow by Iwao (23) the marrow lesions in lymphocytic leukemia appeared to be associated with an increase in number of capillary sinuses, whereas no apparent change from the normal degree of vascularity was observed in the marrow in chronic myelocytic leukemia. Schleicher has also observed an increase in the degree of vascularity in the marrow associated with the patchy and generalized marrow lesions in chronic lymphocytic leukemia. ${ }^{5}$ Such anatomic differences in the vascularity of the marrow may in part explain the findings obtained in the present study. Further detailed anatomic studies are needed with regard to these observations.

The bone marrow cytology and peripheral blood counts could not be related to the increased clearance rates, other than in establishing the diagnoses. While blast cells were present in the marrow in all cases of acute leukemia and appeared to be positively correlated with the rapid clearance rates found in these conditions, few or no lymphoblasts were observed in the chronic lymphocytic leukemia marrows, yet very rapid clearance rates were obtained. In one patient with multiple myeloma (V. W.) almost no cells of any type could be aspirated, yet the clearance rate was very rapid; 16 per cent per minute. These findings suggest that the nature of the vascular bed may be more important in determining the clearance rate rather than the presence or absence of abnormal cells in the marrow.

Although most of the patients studied had chronic anemia, no direct relationship was found between the clearance rate and hemoglobin level (Figures 2 and 3 ).

These preliminary observations give promise that the clearance rates of radioisotopes from the marrow may provide a means for the evaluation of systemic and local influences on the marrow circulation.

\footnotetext{
- Personal communication to authors.
}

\section{SUMMARY AND CONCLUSIONS}

The Kety radioisotope clearance technique with $I^{131}$ has been applied to a study of bone marrow and muscle blood flow in 43 patients with various neoplastic diseases, lymphoblastomas, and leukemias. The marrow clearance rates were found to be approximately the same as resting muscle in all 17 of the non-leukemic patients studied.

In five cases of acute leukemia, marrow clearance rates were increased, being two to three times greater than the rate observed in the non-leukemic group, whereas, in five out of seven patients with chronic myelocytic leukemia, and in two cases of monocytic leukemia, the marrow clearance rates were within the range of the non-leukemic group of patients. In six out of ten patients with chronic lymphocytic leukemia, elevated clearance rates were obtained. Three out of four patients with multiple myeloma had increased marrow clearance rates. When marrow $K$ to muscle $K$ ratios were obtained in the non-leukemic, chronic myelocytic and monocytic leukemic patients, the values fell below 1.4. In two cases of acute leukemia and four out of ten chronic lymphocytic leukemics the ratio obtained was well above 1.4. The findings appear to demonstrate a selective increase in blood flow in the bone marrow in acute leukemia and in some cases of chronic lymphocytic leukemia and multiple myeloma, and strongly suggest that fundamental differences in the marrow vascular bed exist among the leukemic group of diseases.

Alterations were produced in the clearance rates in bone marrow following the intravenous injection of Paredrine and hexamethonium in two patients. The radioisotope clearance technique promises to be a useful tool for the investigation of the pathologic-physiology of the human bone marrow circulation.

\section{ACKNOWLEDGMENT}

We wish to express our appreciation to Dr. Jonah G. Li of the Division of Preventive Medicine, University of California School of Medicine, San Francisco for his cooperation in providing many of the patients for these studies.

\section{REFERENCES}

1. Green, H. D., Methods in Medical Research. Vol. I, Section II, V. R. Potter, Ed., Year Book Publishers, Inc., Chicago, 1948. 
2. Jones, H. B., Medical Physics. Vol. II, Otto Glasser, Ed., Year Book Publishers, Chicago, 1950 , p. 860 .

3. Kety, S., S., Quantitative measurement of regional circulation by the clearance of radioactive sodium. (Proc. Physiol. Soc. Phila., Jan. 20, 1948), Am. J. M. Sc., 1948, 215, 352.

4. Kety, S. S., Measurement of regional circulation by the local clearance of radioactive sodium. Am. Heart J., 1949, 38, 321.

5. Elkin, D. C., Cooper, F. W., Rohrer, R. H., Miller, W. B., Shea, P. C., and Dennis, E. W., The study of peripheral vascular disease with radioactive isotopes. Part I. Surg., Gynec. \& Obst., 1948, 87, 1.

6. Wechsler, R. L., Sokoloff, L., and Kety, S. S., Measurement of hepatic circulation by clearance of radioactive sodium in man. Federation Proc., 1950, 9, 133.

7. Franke, F. R., Boatman, J. B., George, R. S., and Moses, C., Effect of physical factors on radiosodium clearance from subcutaneous and intramuscular sites in animals. Proc. Soc. Exper. Biol. \& Med., 1950, 74, 417.

8. Boatman, J. B., Kendrick, T. R., Franke, F. R., and Moses, C., The use of radioactive iodine, radioactive phosphorus, and radioactive sodium in the determination of cerebral and muscle clearance. J. Lab. \& Clin. Med., 1950, 36, 456.

9. Wisham, L. R., Yalow, R. S., and Freund, A. J., Consistency of clearance of radioactive sodium from human muscle. Am. Heart J., 1951, 41, 810.

10. Rapaport, S. I., Saul, A., Hyman, C., and Morton, M. E., Tissue clearance as a measure of nutritive blood flow and the effect of lumbar sympathetic block on such measures in calf muscle. Circulation, 1952, 5, 594.

11. Leblond, C. P., Advances in Biological and Medical Physics. I. J. H. Lawrence \& J. G. Hamilton, Ed., Academic Press, Inc., New York, 1948, p. 353.

12. Siri, W. E., Isotopic Tracers and Nuclear Radiations, McGraw-Hill Co., New York, 1949.
13. Stone, P. W., and Miller, W. B., Mobilization of radioactive sodium from the gastrocnemius muscle of the dog. Proc. Soc. Exper. Biol. \& Med., 1949, 71, 529.

14. Drinker, C. K., and Yoffey, J. M., Lymphatics, Lymph and Lymphoid Tissue, Harvard University Press, Cambridge, Mass., 1941.

15. Tocantins, L. M., Rapid absorption of substances injected into the bone marrow. Proc. Soc. Exper. Biol. \& Med., 1940, 45, 292.

16. Tocantins, L. M., and O'Neill, J. F., Infusions of blood and other fluids into the general circulation via the bone marrow. Surg., Gynec. \& Obst., 1941, 73, 281.

17. Willis, R. A., Pathology of Tumors, C. V. Mosby Co., St. Louis, 1948.

18. Algire, G. H., and Chalkley, H. W., Vascular reactions of normal and malignant tissues in vivo. I. Vascular reaction of mice to wounds and to normal and neoplastic transplants. J. Nat. Cancer Inst., 1945, 6, 73.

19. Bierman, H. R., Byron, R. L., Jr., Kelly, K. H., and Grady, A., Studies on the blood supply of tumors in man. III. Vascular patterns in the liver by hepatic arteriography in vivo. J. Nat. Cancer Inst., 1951, 12, 107.

20. Benda, R., Orinstein, E., and Depitre, M., Injections intramédulaires osseuses de substances opaques chez l'homme. (Etude comparée des images radiologiques obtenues sur les pièces anatomiques et sur le vivant.) Sang., 1940, 14, 172.

21. Pizzolato, P., The blood supply of the sternum. I. $\mathrm{X}$-ray studies of injected sternums showing venous return. New Orleans M. \& S. J., 1944 1945, 97, 71.

22. Doan, C. A., The circulation of the bone marrow. Contrib. Embryol., 1922, 14, 27.

23. Iwao, T., Über die Knochenmarksbefunde bei Fällen von verschiedenen Blutkrankheiten, besonders uber den Zusammenhang zwischen der Blutbildung und dem Entwicklungsgrad der Kapillarsinus im Knochenmark. Transactiones Societates Pathological Japonica, 1940, 30, 54. 